\title{
Primary Cutaneous Amyloidoma: A Case Report
}

\author{
Julia García Reitboeck Robert Feldmann Dagmara Loader \\ Friedrich Breier Andreas Steiner \\ Department of Dermatology, Municipal Hospital Hietzing, Vienna, Austria
}

\section{Key Words}

Amyloid · Amyloidoma $\cdot$ Amyloidosis $\cdot$ Tumor $\cdot$ Dermatologic surgery

\begin{abstract}
Amyloidoma is defined as solitary, localized, tumor-like deposit of amyloid in diverse organs without evidence of systemic amyloidosis. Here we report the case of a 49-year-old male patient with a solitary amyloidoma of the skin seated on the left upper lip. Full medical examination showed no signs of systemic amyloidosis. The mass was removed surgically with tangential shave and so far no signs of recurrence have been found. 02014 S. Karger AG, Basel
\end{abstract}

\section{Introduction}

Amyloidoma constitutes a solitary, localized, tumor-like deposit of amyloid, i.e. insoluble fibrillar proteins with beta-pleated sheet arrangement, in diverse organs without evidence of systemic amyloidosis [1]. We here report an unusual case of an amyloidoma confined to the skin.

\section{Case Presentation}

A 49-year-old male patient presented to our department with a mass located on the left upper lip and extending to the nostril. The mass had grown in size over the past 4 years and did not cause any symptoms. On examination a skin-colored firm nodule with a smooth surface measuring approximately $2 \times 2 \mathrm{~cm}$ was found (fig. 1). The borders of the lesion were sharply demarcated. The remainder of the skin and general examination was unremarkable. 
García Reitboeck et al. Primary Cutaneous Amyloidoma: A Case Report

A skin biopsy was performed. Histologic examination revealed homogenization of the dermal connective tissue with deposits of amorphous material and featured plasma cells as well as a few giant cells (fig. 2a). Extensive amyloid deposits in the entire dermis were seen on Congo red staining with the characteristic apple-green birefringence under polarized light (fig. 2b). The amyloid type was determined immunohistochemically as ALk amyloid, using the 'amY-kit' including 24 individual amyloid antibodies. A strong reactivity for antiALk was observed.

The patient underwent further investigations. MRI of the head and neck region demonstrated a well-defined local mass near the left upper lip measuring $1.8 \times 2.2 \times 1.7 \mathrm{~cm}$. A CT scan of the skull did not detect any bone lesions. Echocardiography, ultrasound of the abdomen, pelvis and lymph nodes of the neck, axilla, groin, chest X-ray as well as colonoscopy showed no signs of systemic amyloidosis. Blood analysis including immunoglobulins and immunoelectrophoresis were unremarkable.

The mass was removed with tangential shave and a good cosmetic result. At 3-year follow-up no clinical signs of recurrence were found.

\section{Discussion}

Amyloidosis is a large and heterogeneous group of disorders characterized by extracellular deposits of amyloid in individual organs or tissue. Extracellular amyloid consists of unique protein fibrils [2]. Amyloidosis can be hereditary or acquired, and it may either be systemic or localized [3]. The most frequent types of amyloidosis are the AL (primary) and AA (secondary) type. AA amyloidosis can develop in patients with chronic inflammatory conditions such as rheumatoid arthritis or chronic infections (e.g. osteomyelitis or tuberculosis). AL amyloidosis is due to deposition of protein derived from immunoglobulin light chain fragments, e.g. in multiple myeloma or Waldenström's macroglobulinemia, with a monoclonal pattern on serum protein electrophoresis.

Amyloidoma or localized tumoral amyloidosis is the least common presentation of tissue amyloid deposition [4]. It has been reported in many different anatomic regions, mainly the respiratory, genitourinary and gastrointestinal tracts, as well as the nervous system, breast and soft tissue. Amyloidoma of the skin is a very rare condition, and only a few cases have been described in the literature so far [5]. The diagnosis can be established with histologic examination of the involved tissue and, in particular, positive Congo red staining for amyloid [6].

The cause of the pathologic protein deposits is a monoclonal gammopathy proved by the evidence of ALк amyloid, as was confirmed in our patient by immunohistochemistry [7]. The amyloid consists of monoclonal immunoglobulin- $\kappa$ light chain that proves resistant to protein degradation and forms extracellular fibrillar, insoluble deposits with the known specific characteristic of amyloid (i.e. apple-green birefringence under polarized light) [8]. The monoclonal gammopathy may occur in a strictly localized manner and can be considered as an isolated form of plasmocytoma without spreading to other organs.

The treatment of amyloidoma consists of complete surgical resection. In case of partial excision, recurrence is common [9]. Long-term follow-up is required to rule out development of systemic disease. 
García Reitboeck et al.: Primary Cutaneous Amyloidoma: A Case Report

\section{Acknowledgement}

The authors thank Reinhold P. Linke, MD, PhD, for his valuable help by providing the immunohistochemical results. The immunohistochemistry used in this publication was processed in the Reference Center for Amyloid Diseases, amYmed, Martinsried, Germany.

\section{Disclosure Statement}

The authors declare no conflicts of interest or financial support.

\section{References}

1 Mukhopadhay S, Damron TA, Valente AL: Recurrent amyloidoma of soft tissue with exuberant giant cell reaction. Arch Pathol Lab Med 2003;127:1609-1611.

-2 Maheshwari AV, Muro-Cacho CA, Kransdorf MJ, Temple HT: Soft-tissue amyloidoma of the extremities: a case report and review of literature. Skeletal Radiol 2009;38:287-292.

-3 Westermark P: Localized AL amyloidosis: a suicidal neoplasm? Ups J Med Sci 2012;117:244-250.

4 Fierens J, Mees U, Vanbockrijck M, Hendrikx M: Amyloidoma of the chest wall: a rare entity. Interact Cardiovasc Thorac Surg 2008;7:1194-1195.

5 Biewend ML, Menke DM, Calamia KT: The spectrum of localized amyloidosis: a case series of 20 patients and review of the literature. Amyloid 2006;13:135-142.

-6 Willson TD, Bird J, Azizi R, Connoly MM, Podbielski FJ: Extraluminal amyloidoma of the pelvic cavity causing large bowel obstruction. Case Rep Gastroenterol 2011;5:315-319.

7 Linke RP: Classifying of amyloid on fixed tissue sections for routine use by validated immunohistochemistry. Amyloid 2011;18(suppl 1):67-70.

-8 Linke RP, Oos R, Wiegel NM, Nathrath WB: Classification of amyloidosis: misdiagnosing by way of incomplete immunohistochemistry and how to prevent it. Acta Histochem 2006;108:197-208.

-9 Laimer L, Namberger K, Hintner H, Linke RP: Perinasal dermatitis due to a local plasmocytoma with vicinal nodular AL $\lambda$ amyloid. Amyloid 2011;18(suppl 1):103-105.

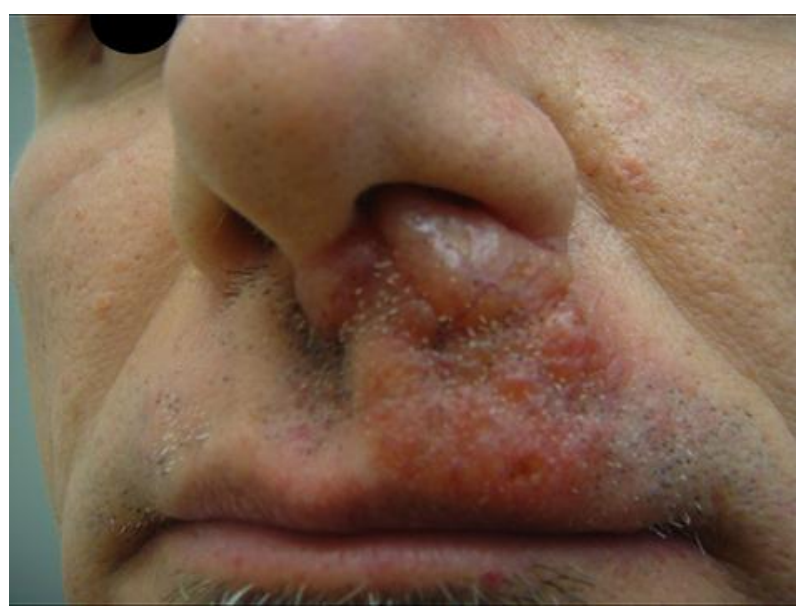

Fig. 1. Primary cutaneous amyloidoma: perinasal mass on the left upper lip with a multinodular surface without ulceration. 

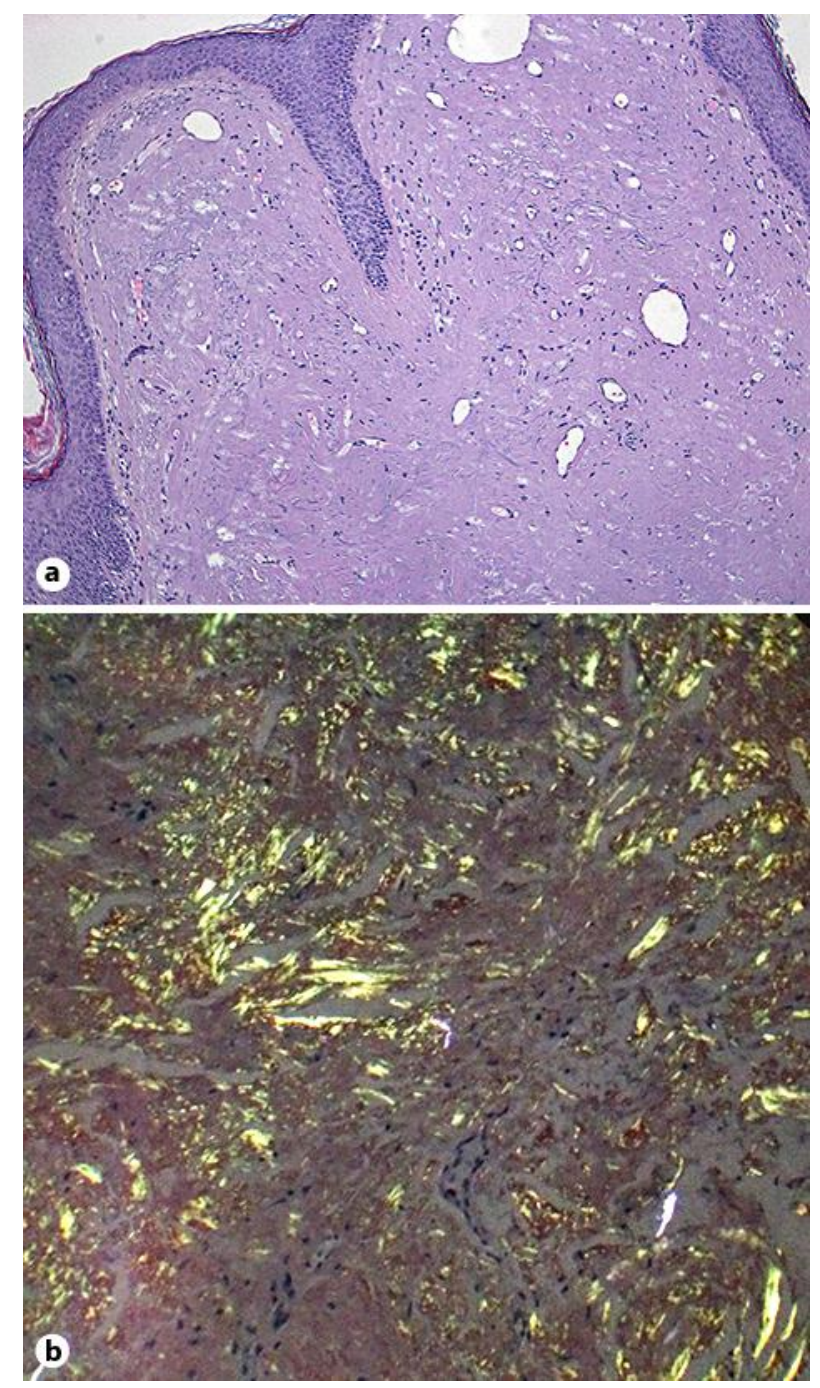

Fig. 2. a Histopathologic findings. The epidermis showed regular stratification. Prominent homogenization between the dilated vessels in the dermis was seen. Hematoxylin-eosin stain, $\times 40$. $\mathbf{b}$ Histopathologic findings. Typical apple-green birefringence under polarized light was seen. Congo red stain, $\times 100$. 